\title{
Tracking Hurricanes using GPS atmospheric precipitable water vapor field
}

\author{
Yohannes Getachew Ejigu · Felix Norman Teferle · Anna Klos · Janusz Bogusz · \\ Addisu Hunegnaw
}

Received: date / Accepted: date

\begin{abstract}
Tropical cyclones are one of the most powerful severe weather events that produce devastating socioeconomic and environmental impacts in the areas they strike. Therefore, monitoring and tracking of the arrival times and path of the tropical cyclones are extremely valuable in providing early warning to the public and governments. Hurricane Florence struck the East cost of USA in 2018 and offers an outstanding case study. We employed Global Positioning System (GPS) derived precipitable water vapor (PWV) data to track and investigate the characteristics of storm occurrences in their spatial and temporal distribution using a dense ground network of permanent GPS stations. Our findings indicate that a rise in GPS-derived PWV occurred several hours before Florence's manifestation. Also, we compared the temporal distribution of the GPS-derived PWV content with the precipitation value for days when the storm appeared in the area under influence. The study will contribute to quantitative assessment of the complementary GPS tropospheric products in hurricane monitoring and tracking using GPS-derived water vapor evolution from a dense network of permanent GPS stations.
\end{abstract}

Keywords GPS · precipitable water vapor - Tropical cyclones · hurricane Florence

\section{Ejigu Y. G.}

Department of Space Science and Application Research Development, Ethiopian Space Science and Technology Institute (ESSTI), Addis Ababa, Ethiopia

Department of Physics, Wolkite University, Wolkite, Ethiopia

E-mail: john.yohannes200@gmail.com

Teferle F. N., and Hunegnaw A.

Geodesy and Geospatial Engineering, Institute of Civil and Environmental Engineering, University of Luxembourg, Luxembourg.

Klos A., and Bogusz J.

Faculty of Civil Engineering and Geodesy, Military University of Technology, Warsaw, Poland

\section{Introduction}

Historical Tropical cyclones (TC) records from the National Hurricane Center (NHC) indicate that 916 hurricanes were formed in the Atlantic basin between 1851 and 2018, of which 330 are major hurricanes with Saffir-Simpson scale 3,4 or $5^{1}$. Over the years, their dissipation of power has increased as the strengths of hurricanes have intensified (Klotzbach, 2006; Elsner et al, 2008; Bhatia et al, 2019). Hurricane Florence was one of the category 4 major hurricanes during the 2018 Atlantic hurricane season that produced the largest freshwater flooding in the Carolinas, USA. The consequence was that produced catastrophe and life-threatening flooding. The fundamental physics of TC is a complex process that is fueled by a combination of warm ocean water, moist air and winds (Emanuel et al, 2006). The band of air and wind that surrounds the eye of TC acts as a conduit for vertical wind that drags water vapor up from the warm ocean surface (Emanuel, 1999; Kepert, 2010). The transfer of this energy occurs mainly through the evaporation of water into the atmosphere consequently boosting the radial circulation within the storm by conserving the rotational momentum of rotating air (Smith, 2000; Emanuel, 2003). The convection systems rely on the atmosphere of the water vapor and vertical temperature profiles in the convection region. Thus, the role of atmospheric water vapor information is very valuable in the study, monitoring and prediction of the TC.

Water vapor is a key component in the atmosphere's thermodynamics. It transports latent heat, contributes to absorption and emission in a number of bands and condenses into clouds reflecting and adsorbing solar radiation. Therefore, it directly affects the energy balance. Severe meteorological events such as a hurricane emphasize the need to monitor and track using additional observational tools to mitigate

\footnotetext{
${ }^{1}$ https://www. aoml.noaa.gov/hrd/tcfaq/E11.html
} 
the risks. Traditionally, the water vapor data has been acquired primarily through the use of water vapor radiometers (WVR) and radiosondes for many years. These techniques of acquiring water vapor data enabled major progress in understanding the procedures happening in the atmosphere, while suffered drawbacks like their low spatial-temporal resolution and high operating costs (Gaffen et al, 1992).

Nowadays, developments in satellite remote sensing technologies offer a wide range in global observations of various structural features of meteorological parameters. The GPS measurement of water vapor is considered one of the key observational tools because GPS works in all weather conditions, unlike other passive remote sensing techniques (Rocken et al, 1995; Zhang et al, 2015). Therefore, GPS has become a defacto standard technique for measuring water vapor with a notable benefit over other traditional meteorological sensors. The propagation delay that affects GPS signals depends on the amount of water vapor in the atmosphere (Bevis et al, 1992). This water vapor sensitivity of GPS delay measurements has been used to derive the precipitable water vapor (PWV) in the atmosphere. Rocken et al (1995) conducted the first GPS/STORM experiment using GPS meteorology techniques under extreme weather conditions, in a tornado high risk area in the Midwest of the USA. Zhang et al (2015) have shown the spatio-temporal distributions of GPS-PWV to monitor and predict the typical aspects of typhoons, albeit using a limited number of GPS stations and capable of capturing the signature of severe weather. Recently, Graffigna et al (2019) showed a significant change in ZTD gradients before a tropical storm arrived. In regions around dense clouds and heavy precipitation, GPS provides independent measurements of atmospheric processes where visible, infrared and microwavebased satellite measurements are largely contaminated (Vergados et al, 2013).

GPS-derived tropospheric products are currently used to investigate meso-scale weather systems and near-real-time applications (Falvey and Beavan, 2002; Nakamura et al, 2004; Kawabata et al, 2013; Bordi et al, 2015). With these troposphere products being assimilated into forecast numerical weather prediction (NWP) models (Wilgan et al, 2015; Zus et al, 2015) and thus demonstrate a positive impact on shortrange moisture field forecasts and ultimately improve precipitation predictions for severe rainfall events (Bennitt and Jupp, 2012). Developments in real-time GPS and of nowcasting NWP models make this application possible by providing PWV that complementing to some level the meteorological predictions ( $\mathrm{Li}$ et al, 2015). Since PWV relates to the mass of clouds and the dynamics of the temperature near the surface, it is one of the main drivers of the meteorological processes that determine our weather and, in particular, precipitation. The GPS tropospheric products can be used to determine the spacial and temporal change of water vapor, thus help to understand the complex properties of a storm (Tahami et al, 2017; Ejigu et al, 2019a,b). Furthermore, in areas where a dense network of GPS stations is available, it is possible to produce high resolution GPS-PWV maps for the investigation of spatio-temporal water vapor changes. Thus, the use of GPS tropospheric products for regional severe storm prediction is a current research topic and an application that the geodetic community wishes to promote within the meteorological groups. Besides, recent studies have investigated the accuracy of GPS tropospheric products by identifying factors that affect their quality when GPS data are processed (Kačmařík et al, 2017; Klos et al, 2018; Ejigu et al, 2018).

One of the main motivations of this study is to monitor and track early stages of a hurricane (e.g. Hurricane Florence) in 2018 from GPS-derived PWV. We have derived the PWV from the zenith total delay (ZTD) estimation using mean weighted temperature and surface pressure meteorological information. The accuracy of the temporal distribution of the GPS-derived PWV datasets has been validated by comparing with the precipitation value for days when the storm appeared in the area under influence. Also, the accuracy of the GPS-derived PWV datasets has been validated by comparison with the PWV from the radiosonde. Radiosondes are widely used for understanding meteorological parameters in the vertical direction. We emphasis on capturing the signature of major Hurricane Florence events using atmospheric water vapor field information obtained from GPS measurements in the USA. We show how PWV can be used to track and monitor the future hurricanes. The capability of a dense GPS network (i.e. those with antennas only 10s of kilometers apart) to make observations at the required high spatial resolution is being investigated. In this regard, the study objective is to assess the connection between the temporal evolution of GPS-derived PWV and its influence on TC structure. This GPS-derived PWV product may serve as an additional input parameter for hurricane numerical weather prediction (NWP) models.

\section{Data and Methods}

\subsection{Retrieval of PWV from GPS ZTD}

We selected a dense network of permanent GPS stations (Fig.1a). The network was in the area affected by Hurricane Florence and includes more than 839 GPS stations for a period of over two months (before, during and after Florence), from 24 August to 10 October 2018, distributed of nearly 20-km inter-stations distance across the Carolinas.

We have used the zenith total delay (ZTD) of Tropo-SINEX formatted (Gendt, 1997) obtained from the Nevada Geodetic Laboratory (NGL) which employs the GIPSY/OASIS-II 
software in a precise point positioning (PPP) strategy (Zumberge et al, 1997; Bertiger et al, 2010; Teunissen and Khodabandeh, 2014). The solutions are freely available at the NGL Tropo-SINEX ftp data server ${ }^{2}$. The NGL Tropo-SINEX files have a five-minute temporal resolution. The observation cutoff angle was 7-degree. The satellite clocks, receiver clocks, station coordinates, integer ambiguity and total zenith delays were estimated. The estimated ZTD delay and the horizontal tropospheric gradients (East-West and North-South) are allowed to vary within random walk $5.0 e^{-8} \mathrm{~km} / \sqrt{\mathrm{sec}}$ and $5.0 e^{-9} \mathrm{~km} / \sqrt{\mathrm{sec}}$, respectively. Global Mapping Function (Böhm et al, 2006a) was applied to map slant path delays along GPS signals to ZTD. Details on the GPS observation processing strategy summary are available at the relevant Analysis Center code (ACN) file from NGL website 3 . The ZTD can be further split into zenith hydrostatic delay (ZHD) and zenith wet delay (ZWD). The ZHD can be determined precisely by measuring the surface pressure $\left(P_{S}\right)$ at the station position (Saastamoinen, 1972),

$$
Z H D=\frac{(2.2768 \pm 0.0015) P_{s}}{1-2.66 \times 10^{-3} \times \cos (2 \phi)-2.8 \times 10^{-7} h}
$$

where $h$ is the station height in meters above the ellipsoid. The formal error of equation (1) $( \pm 0.0015 \mathrm{~mm} / \mathrm{hPa})$ was calculated by considering that all uncertainties of the $P_{s}$ and $h$ parameters are uncorrelated and this can be found in Davis et al (1985). We calculated ZHDs using data available from the Vienna Mapping Functions (VMF) gridded files (Böhm et al, 2006b). In GPS meteorology, it is common practice to extract ZWD directly by subtracting ZHD from the estimated ZTD (Bevis et al, 1992). Further, we calculated PWV using

$$
P W V=\frac{Z W D}{10^{-6}\left(K_{2}^{\prime}+\frac{K_{3}}{T_{m}}\right) R_{v} \rho}
$$

where $K_{2}^{\prime}=22.1 \pm 2.2 \mathrm{~K} / \mathrm{hPa}$ and $K_{3}=3.739 \pm 0.012 \times$ $10^{5} K^{2} / h P a$ are physical atmospheric reflectivity constants (Bevis et al, 1992), $\mathrm{Rv}=461(\mathrm{Jkg} / \mathrm{K})$ represents the ideal gas constant for water vapor, $\rho$ is the density of the water vapor, and $T_{m}$ is the atmospheric column mean weighted temperature.

The $T_{m}$ is an essential parameter for retrieving PWV from the ZWD of GPS signal propagation. We obtained the grid format $T_{m}$ measurements from VMFG data website. ${ }^{4}$ The VMF observed surface pressure and $T_{m}$ are derived from the European Center for Medium-Range Weather Forecasts (ECMWF) reanalysis dataset. Then we applied a bilinear interpolation technique to extract $T_{m}$ at the station height. Furthermore, we have carried out the uncertainty of the GPSderived PWV before conducting the analysis based on an approach similar to the one used by (Ning et al, 2013).

\footnotetext{
2 ftp://gneiss.nbmg.unr.edu/trop/

3 http://geodesy.unr.edu/gps/ngl.acn

4 http://vmf.geo.tuwien.ac.at
}

\subsection{Precipitation datasets}

We obtained the precipitation data from the recent Integrated Multi-Satellite Retrievals for Global Precipitation Measurement (GPM/IMERG) satellite mission. The GPM/IMERG datasets is produced by NASA Goddard Earth Sciences (GES) team, which provides a combined microwave and infrared (IR) satellite gridded precipitation estimates. The GPM/IMERG has 0.1 degree and half-hour spatio-temporal resolutions for microwave and Infra-red (IR), respectively. The complete algorithm and description are accessible from Huffman et al (2017). We also compared the precipitation measurements from the Tropical Rainfall Measuring Mission (TRMM)'s three-hour combined Level-3 microwave-IR estimates (3B42 product, version-7). The purpose of the $3 \mathrm{~B} 42$ product is to produce tropical rainfall measurements and rain gauge-adjusted precipitation rates merged with other satellite mission measurements. This datasets has a three-hour temporal resolution and $0.25 \times 0.25$ degree spatial resolution (Huffman and Bolvin, 2015). We cover the period of 24th August to 10th October the 2018 hurricane season.

\subsection{Radiosonde Data}

Meteorologists use radiosondes as one of their main traditional techniques to measure the water vapor content in the atmosphere at various heights with the balloon ascending. Modern radiosondes measure PWV with an accuracy of a few millimeters (Niell et al, 2001). By using radiosonde profiles, the atmospheric PWV content can be estimated in a vertical column of a cross-sectional unit area extending between any two pressure levels. It is usually defined in terms of the height at which the PWV content would lie if it was fully condensed and gathered in a vessel cross-section of the same unit. The integration of PWV contained in every column of unit cross-sectional extending from the surface to the top of the atmosphere is defined as total PWV.

In this paper, the radiosonde sounding PWV data were obtained from the University of Wyoming archives ${ }^{5}$ for a period of 24 August to 30 October in the 2018 hurricane season. This archive provides high-quality meteorological parameters such as pressure, temperature and relative humidity at various altitudes (Durre et al, 2016). The radiosonde data has a low temporal rate (mostly operating twice per day, often related to running costs) and that limits their applications in short-term weather forecasting. Furthermore, radiosondes drift laterally than ascending, hence their measurements are not strictly vertical above the radiosonde location.

\footnotetext{
5 http://weather.uwyo.edu/upperair/sounding.html
} 


\section{Results}

\subsection{GPS-derived PWV and hurricane Florence}

Using a dense ground network of permanent GPS stations, it is possible to pierce through the atmosphere to quantify the distribution of water vapor present and obtain PWV measurement between the GPS station and the GPS satellite in the local zenith direction. Figure $1 \mathrm{~b}$ presents the stacked GPS-PWV time series for Hurricane Florence, together with the satellite rainfall product from GPM/IMERG and TRMM time series associated with this event. Stations that were within the perimeter of the red rectangle shown in Figure 1a are employed for stacking to understand the PWV characteristics as the storm approaches(i.e, we take a simple sort of stacking for the PWV six-hour resolution time series of each station and produce a simple average as a representative time series for hurricane Florence landfalls and large distraction area). For these, the influence of Florence is regarded as maxima.

In the 2018 hurricane season, Florence largely affected the Southeastern United States, and we stacked all available GPS stations' PWV time series around the South Carolina area over a period of two-months, from 24 August to 10 October. The GPS-PWV time series demonstrated maximum values during the storm front's passage over the respective area. It displays that the time series of PWV at all stations used for stacking are consistent. The GPS-PWV of 74-mm and more was reached on 15/16-September 2018 when Florence crossed from the North Carolina-South Carolina border eastward across Southeastern North Carolina.

We also show the daily cumulative GPM/IMERG and TRMM precipitation attributable to storm from 24-August to 10October for comparison (Fig.1b, blue line). Most of the precipitation occurred from 14-17 September. The daily cumulative GPM/IMERG precipitation exceed 20-cm over Southeastern North Carolina as Florence passed over the city. Figure 1c shows the standard deviation (STDev) for the GPSPWV for all stations stacked. During GPS data processing, the quality of GPS-PWV can be evaluated from the ZTD law of error propagation. The estimation error is extracted from the residual of the constrained least square solution. The maximum STDev for PWV reaches $0.8 \mathrm{~mm}$. However, $95 \%$ of the STDev are below $0.6 \mathrm{~mm}$ and on average at 0.5 $\mathrm{mm}$. We show scatter plots of GPS-PWV versus precipitation from TRMM (Fig.1d). We have made a three-hour interval resolution for regression analysis based on the maximum value of GPS-PWV and precipitation events for one week (between 14-18 September). These parameters exhibit a good strong coupling and follow a similar footprint associated with the storm, with a Pearson correlation of up to $69 \%$ with GPM/IMERG and $66 \%$ with TRMM.

\subsection{Accuracy of GPS-derived PWV}

Radiosondes data are often used as a source for independent validation to demonstrate the quality of the GPS-derived PWV field. However, to correctly assess the GPS PWV precision during severe weather periods, it is essential to use more reliable and more precise devices, such as a water vapor radiometer (WVR). Liou et al (2001) shows the consistency of radiosonde (RS) PWV estimates depends on the degree of atmospheric in-homogeneity.

To determine the quality of PWV derived from GPS, the radiosonde measurements of PWV from two nearby stations at Charleston (CHS) located at $\left[27.76^{\circ} \mathrm{N}, 97.50^{\circ} \mathrm{W}\right]$ and Greensboro (GSO) located at $\left[30.11^{\circ} \mathrm{N}, 93.21^{\circ} \mathrm{W}\right]$ were used for the comparison of GPS-derived PWV in addition to assessment of formal error propagation. The RS stations CRP and $\mathrm{LCH}$ are approximately located at 13 and $15 \mathrm{~km}$ from the GPS stations SCFJ and HITP, respectively. It is required that the horizontal and vertical separation between RS and GPS stations should be less than $50 \mathrm{~km}$ and $100 \mathrm{~m}$, respectively (Wang and Zhang, 2008).

Generally, the distribution of RS stations is very sparse and nonuniform. As a result, it is rare to find a RS station very close to a GPS stations. Figure 2 demonstrates the comparison of PWV obtained from the GPS and RS observations for the period between 20 August to 10 October 2018 (covering the time period of pre-, during- and post-Florence). From Figure 2, we found a strong and consistent degree of correlation with values between $94 \%$ and $95 \%$. The difference between RS and GPS derived PWV shows an RMS of 2.8 and $2.5 \mathrm{~mm}$, which is consistent with values from previous comparisons (Deblonde et al, 2005; Ejigu et al, 2018; Li et al, 2003). This provides us an external validation of our GPSderived PWV estimates data-sets. Our GPS-derived PWV, however, is at higher temporal and spatial resolutions than these from the RS data.

\subsection{Estimating GPS PWV distribution maps and monitoring of hurricane Florence}

To quantify how well a storm was captured by GPS-PWV, we constructed water vapor maps using a well-distributed GPS station network and compared the temporal distribution of the GPS-PWV content with the precipitation value for days when the storm appeared in the area. Figure 3 depicts the daily mean GPS-PWV evolution, and the daily cumulative GPM/IMERG precipitation, for Florence from 13 to 18 September 2018. On 30 August, Florence was accompanied by a broad low pressure system that moved off the west coast of Africa. Florence held a steady west-northwest motion at about 15 knots for the next several days as it passed around the Southern periphery of a broad Bermuda-Azores ridge extending from northwestern Africa and Southern Europe 

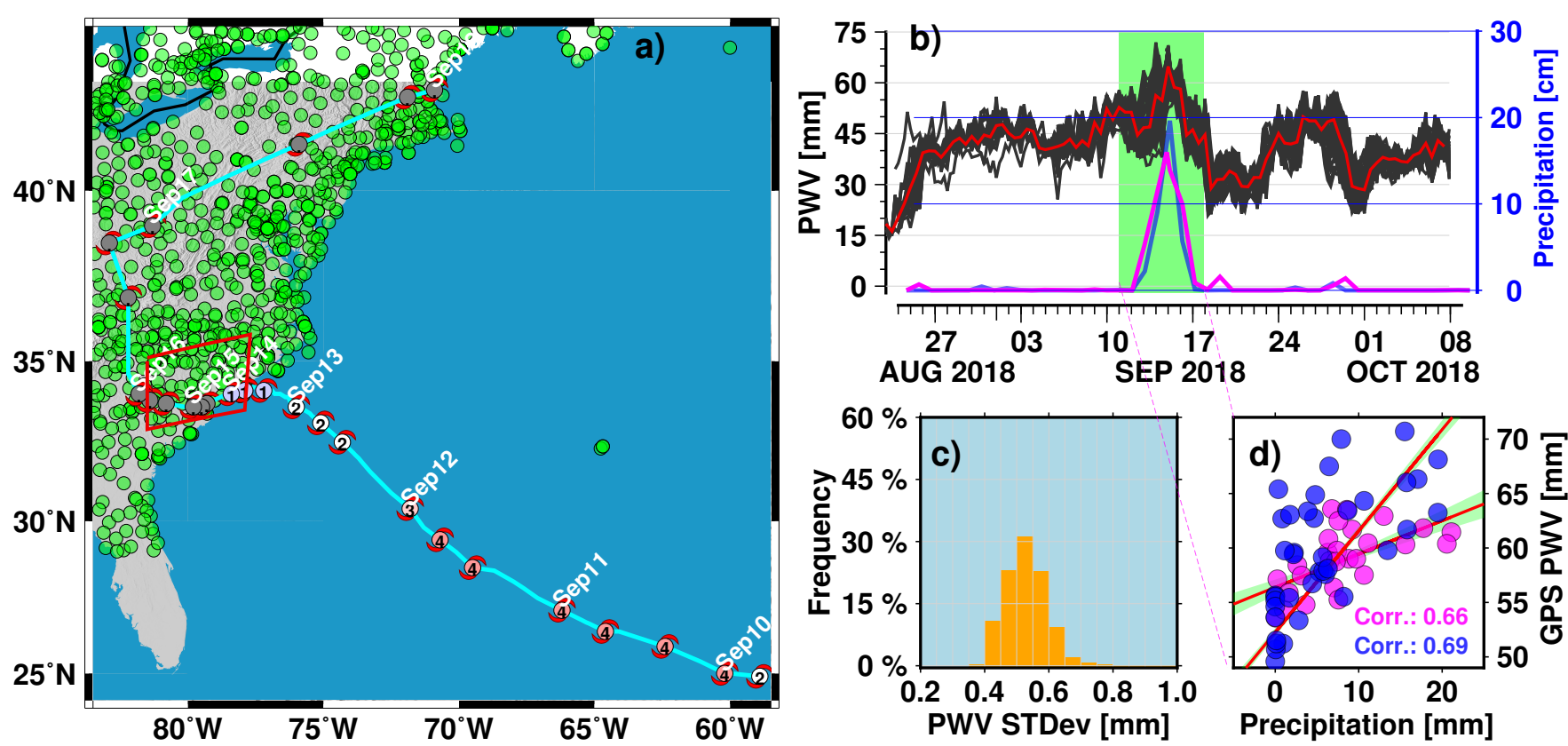

Fig. 1 a) Distribution of GPS stations shown as green circles. The cyan line is the actual path of Florence. The numbers on this line indicates the categories of the hurricane. b) Six-hours resolution stacked time series of GPS-PWV of individual GPS stations (black-lines) and averaged (red-line); stations within the red rectangle shown in panel map (a) are employed for a simple stacking. Superimposed are the daily accumulated GPM/IMERG (blue-line) and TRMM (magenta-line) precipitation time series. The light-green shaded region illustrates the periods where Florence shows a maximum change in GPS-PWV and precipitation. c) Histogram of the standard deviation (STDev) for GPS-PWV. The histogram was generated from the six-hour resolution stacked time series for the set of around 839 distributed stations for a period of two months in 2018 . d) Scatter plot represents the regression between satellite-derived precipitation (i.e, GPM/IMERG is in blue-circles and TRMM is in magenta-circles) and GPS-PWV. The red line is the estimated linear regression and the green shadow is the 95\% confidence interval. The regression is carried out with a three-hour resolution over the time periods of maximum change in GPS-PWV (i.e. 13-18 August 2018, i.e the light-green shaded regions).
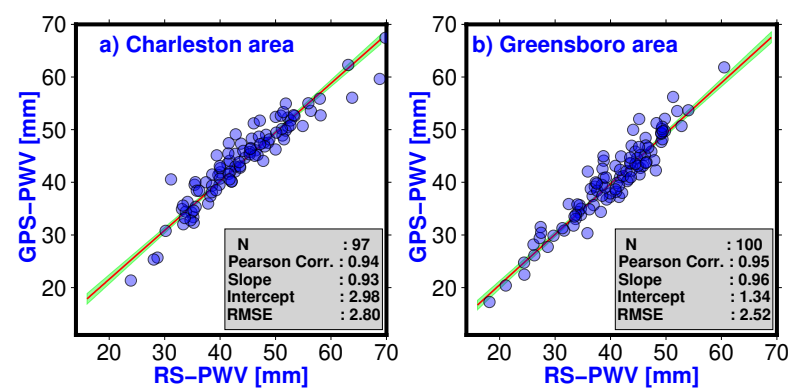

Fig. 2 Regression of PWV from GPS and radiosonde measurements at two stations; (a) The RS station at Charleston and GPS station SCFJ, and (b) the RS station at Greensboro and GPS station HIPT. The period covers from 24 August to 10 October 2018 at an interval of 12-hour temporal resolutions. The red line is the estimated linear regression and the green shadow that underlying in the red line is the $95 \%$ confidence interval. The number of data samples (N), Pearson correlation, slope, intercept and root mean square error (RMSE) are given in the legends.

west to the east coast of the United States (Stacy and Robbie, 2019). It then began to intensify and turn into a hurricane on 04 September. On 13 September, Florence moved closer to the North Carolina coast, and by 14 September it had moved inland. Also, the PWV values extended to rise at a fairly rapid rate. The dramatic increase illustrates the effect of the hurricane. The driver behind this change is mainly owing to the increase of the partial pressure of water vapor (Seco et al,
2009), which is intimately linked to the ZWD. The GPSPWV increased considerably when Florence reached in the East-Southeast of Wilmington, North Carolina area, around 13-17 September. Significant and intense a daily cumulative precipitation reached up to $20 \mathrm{~cm}$ were found over area from Wilmington coast, and by 14 September had moved inland to Elizabethtown, North Carolina. Again it is clear that the GPS-PWV charts successfully capture the passage of the storm and a significantly elevated PWV $(65-71 \mathrm{~mm})$ is observed for 14 September when Florence made landfall at Wrightsville Beach, North Carolina as a Category 1 hurricane. In addition, we see that the GPS-PWV strengthened further and centered on the storm location, and that maximum PWV moved with the storm center. Following this landfall, and then after the passage of the storm, the PWV magnitude decreased, and the daily cumulative precipitation in Carolinas also fell dramatically, to less than $1 \mathrm{~mm}$. Also, the 6-hourly estimated PWV spatio-temporal evolution for the Florence are depicted in the Figures S1, S2 as part of the supplementary material. Likewise, a 6-hourly animated video of the PWV field, which are very well synchronized with Florence for the one week period is included as dynamic contents in the supporting materials. 


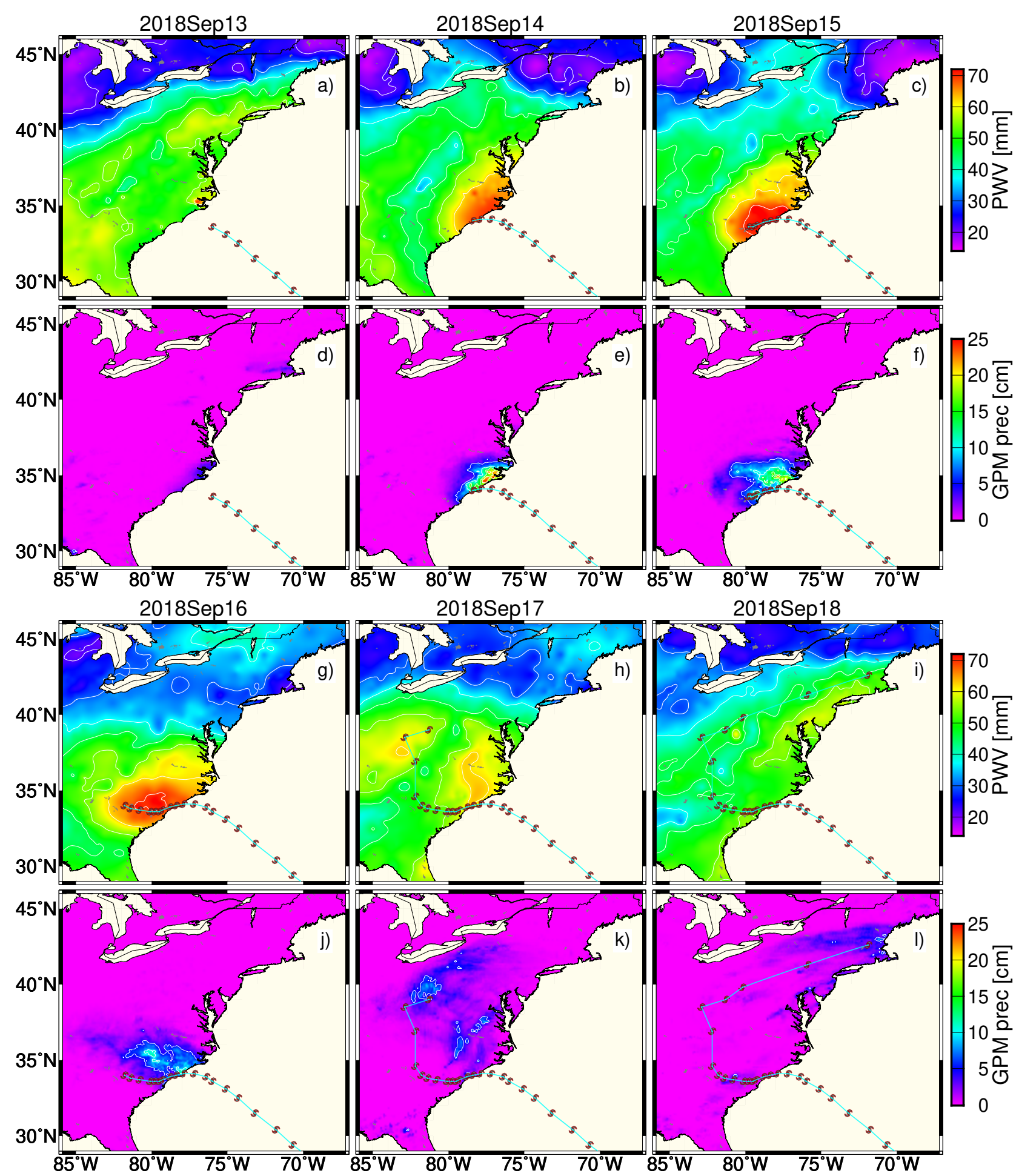

Fig. 3 Daily distribution maps for Hurricane Florence. GPS-PWV (first row $\mathbf{a}-\mathbf{c}$ and third row $\mathbf{g}-\mathbf{i}$ ) and daily accumulated precipitation from GPM/IMERG (second row $\mathbf{d}-\mathbf{f}$ and fourth row $\mathbf{j}-\mathbf{l}$ ) during Florence between 13 to 18 September 2018. The PWV and precipitation maps were created using the Generic Mapping Tools (GMT) by spherical surface spline griding. The contour interval of the GPS-PWV is $7 \mathrm{~mm}$, and the GPM/IMERG precipitation is $5 \mathrm{~cm}$. The precipitation values are from GPM/IMERG. Florence's path is plotted as the cyan line and the hurricane symbol as brown, respectively. 


\section{Outlook and Conclusions}

In this study, we examined a detailed analysis of the impact of the present-day GPS product PWV during hurricane Florence, which affected the Southeastern United States as category four from 13 to 18 September 2018. The time series PWV data for before, during and after Florence storm were examined. The variation in the time series of the PWV content can be correlated with variations in the precipitation value (from GPM and TRMM) coinciding with the passing of a hurricane storm front. According to Sapucci et al (2016), a sharp increase in the GPS-PWV occurs before rainfall and most of the maximum rainfall occurs near the PWV peak. As it is evident in the comparison, stations around eastern North Carolina (the area where Florence had caused a significant storm surge flooding) showed a sharp peak in PWV during the time Florence was passing. This shows that GPS-derived PWV can be used to monitor Hurricane Florence over the Carolinas. Hence, when the water vapor condenses into clouds or rain, it releases latent heat and thus GPS measurements of water vapor can contribute to track the tropical cyclones. In particular, for 14-18 September in the Carolinas the PWV surged, to reach up to $74 \mathrm{~mm}$ much higher than a typical value of $40 \mathrm{~mm}$. The increase in PWV by an average of $28 \mathrm{~mm}$ (with a range of about 46$74 \mathrm{~mm}$ ) is commonly observed in the general vicinity of the area crossed by a storm for four to five days. There is some variability in water vapor due to the local weather processes during pre-storm. As researchers have reported previously (e.g., Bryan and Oort, 1984; Cadet and Nnoli, 1987), in summer the water vapor intensity is elevated compared to that in other seasons in the Atlantic Ocean. We also observed a sudden drop in the PWV time series values after the storms had passed.

The main advantage of GPS-PWV from a dense continuous GPS network is that it is possible to produce PWV distribution maps in close proximity to real-time or near real time. We constructed the map of maximum possible GPS-derived PWV distribution. We observed a large proportion of PWV in the distribution maps of PWV and were able to determine the feature of the storm. The findings verified that the temporal variation in GPS-PWV is tightly related to the route of the hurricane, possibly tracking and monitoring hurricane operations that rises typically at least several hours prior to the storm's arrival.

Further, the accessibility of ground-based GPS in all weather conditions around the globe and inexpensive GPS receiver are cost-effective meteorological sensors. Also, real-time GPS makes PWVs possible at five-minutes updates. These developments provide the background for the inclusion of realtime GPS in nowcasting models for severe events. Moreover, assimilated GPS-PWV could significantly improve the moisture fields within the nowcasting NWP model, result- ing in a better description of the water budget, and thus will further improve our ability to track and monitoring storms and their impact on e.g coastal communities.

Acknowledgements The ZTD Tropo SINEX data are provided by the Nevada Geodetic Laboratory (NGL) at the University of Nevada, Reno. We used precipitation data from the TRMM and GPM/IMERG satellite missions, provided by the NASA Goddard Space Flight Center and accessed at https://pmm.nasa.gov/data-access/. Anna Klos is supported by the Foundation for Polish Science (FNP). Janusz Bogusz is funded by the Polish National Science Center grant no. UMO2016/21/B/ST10/02353. Addisu Hunegnaw is funded by the Luxembourg National Research Fund/Fonds National de la Recherche (FNR) with project code O18/12909050/VAPOUR/.

\section{References}

Bennitt GV, Jupp A (2012) Operational Assimilation of GPS Zenith Total Delay Observations into the Met Office Numerical Weather Prediction Models. Monthly Weather Review 140(8):2706-2719

Bertiger W, Desai SD, Haines B, Harvey N, Moore AW, Owen S, Weiss JP (2010) Single receiver phase ambiguity resolution with GPS data. Journal of Geodesy 84(5):327337

Bevis M, Businger S, Herring TA, Rocken C, Anthes RA, Ware RH (1992) GPS meteorology: Remote sensing of atmospheric water vapor using the global positioning system. Journal of Geophysical Research: Atmospheres 97(D14):15,787-15,801

Bhatia KT, Vecchi GA, Knutson TR, Murakami H, Kossin J, Dixon KW, Whitlock CE (2019) Recent increases in tropical cyclone intensification rates. Nature Communications 10(1)

Böhm J, Niell A, Tregoning P, Schuh H (2006a) Global Mapping Function (GMF): A new empirical mapping function based on numerical weather model data. Geophysical Research Letters 33(7)

Böhm J, Werl B, Schuh H (2006b) Troposphere mapping functions for GPS and very long baseline interferometry from European Centre for Medium-Range Weather Forecasts operational analysis data. Journal of Geophysical Research: Solid Earth 111(B2), DOI 10.1029/ 2005JB003629

Bordi I, Raziei T, Pereira LS, Sutera A (2015) Ground-based gps measurements of precipitable water vapor and their usefulness for hydrological applications. Water resources management 29(2):471-486

Bryan F, Oort A (1984) Seasonal variation of the global water balance based on aerological data. Journal of Geophysical Research: Atmospheres 89(D7):11,717-11,730, DOI 10.1029/JD089iD07p11717

Cadet D, Nnoli N (1987) Water vapour transport over africa and the atlantic ocean during summer 1979. 
Quarterly Journal of the Royal Meteorological Society 113(476):581-602

Davis JL, Herring TA, Shapiro II, Rogers AEE, Elgered G (1985) Geodesy by radio interferometry: Effects of atmospheric modeling errors on estimates of baseline length. Radio Science 20(6):1593-1607, DOI 10.1029/ RS020i006p01593

Deblonde G, MacPherson S, Mireault Y, Hroux P (2005) Evaluation of gps precipitable water over canada and the igs network. Journal of Applied Meteorology - J APPL METEOROL 44:153-166, DOI 10.1175/JAM-2201.1

Durre I, Vose RS, Yin X, Applequist S, Arnfield J (2016) Integrated Global Radiosonde Archive (IGRA) Version 2. DOI 10.7289/V5X63K0Q

Ejigu GY, Teferle FN, Klos A, Bogusz J, Hunegnaw A (2019a) Improved monitoring and tracking hurricanes using GPS atmospheric water vapor. EGUGA p 17823

Ejigu YG, Hunegnaw A, Abraha K, Teferle FN (2018) Impact of GPS antenna phase center models on zenith wet delay and tropospheric gradients. GPS Solut 23(4):659680

Ejigu YG, Teferle FN, Hunegnaw A, Klos A, Bogusz J (2019b) Tracking hurricanes Harvey and Irma using GPS tropospheric products. AGU Fall Meeting, Dec 2019

Elsner JB, Kossin JP, Jagger TH (2008) The increasing intensity of the strongest tropical cyclones. Nature 455

Emanuel K (1999) Thermodynamic control of hurricane intensity. Nature 401:665-669

Emanuel K (2003) Tropical Cyclones. Annual Review of Earth and Planetary Sciences 31(1):75-104

Emanuel K, Ravela S, Vivant E, Risi C (2006) A Statistical Deterministic Approach to Hurricane Risk Assessment. Bulletin of the American Meteorological Society 87(3):299-314

Falvey M, Beavan J (2002) The Impact of GPS Precipitable Water Assimilation on Mesoscale Model Retrievals of Orographic Rainfall during SALPEX'96. Monthly Weather Review 130

Gaffen DJ, Elliott WP, Robock A (1992) Relationships between tropospheric water vapor and surface temperature as observed by radiosondes. Geophysical Research Letters 19(18):1839-1842, DOI 10.1029/92GL02001

Gendt G (1997) SINEX TRO-solution (Software/technique) independent exchange format for combination of TROpospheric estimates Version 0.01, 1 March 1997. URL https://igscb.jpl.nasa.gov/igscb/data/ format/sinex_tropo.txt

Graffigna V, Hernández-Pajares M, Gende M, Azpilicueta F, Antico P (2019) Interpretation of the tropospheric gradients estimated with gps during hurricane harvey. Earth and Space Science 6(8):1348-1365

Huffman GJ, Bolvin D (2015) TRMM and Other Data Precipitation Data Set Documentation. NASA pp 1-44
Huffman GJ, Bolvin D, Eric N J (2017) Integrated MultisatellitE Retrievals for GPM (IMERG) Technical Documentation. NASA pp 1-46

Kačmařík M, Douša J, Dick G, Zus F, Brenot H, Möller G, Pottiaux E, Kapłon J, Hordyniec P, Václavovic P, Morel L (2017) Inter-technique validation of tropospheric slant total delays. Atmospheric Measurement Techniques 10(6):2183-2208

Kawabata T, Shoji Y, Seko H, Saito K (2013) A Numerical Study on a Mesoscale Convective System over a Subtropical Island with 4D-Var Assimilation of GPS Slant Total Delays. Journal of the Meteorological Society of Japan 91:705-721

Kepert JD (2010) Global Perspectives on Tropical Cyclones. WORLD SCIENTIFIC

Klos A, Hunegnaw A, Teferle FN, Abraha KE, Ahmed F, Bogusz J (2018) Statistical significance of trends in zenith wet delay from re-processed gps solutions. GPS Solutions 22(2):51

Klotzbach PJ (2006) Trends in global tropical cyclone activity over the past twenty years (19862005). Geophysical Research Letters 33(10)

Li X, Dick G, Lu C, Ge M, Nilsson T, Ning T, Wickert J, Schuh H (2015) Multi-gnss meteorology: Real-Time Retrieving of Atmospheric Water Vapor From BeiDou, Galileo, GLONASS, and GPS observations. IEEE Transactions on Geoscience and Remote Sensing 53(12):63856393

Li Z, Muller JP, Cross P (2003) Comparison of precipitable water vapor derived from radiosonde, GPS, and Moderate-Resolution Imaging Spectroradiometer measurements. Journal of Geophysical Research: Atmospheres 108(D20), DOI 10.1029/2003JD003372

Liou YA, Teng YT, Van Hove T, Liljegren JC (2001) Comparison of Precipitable Water Observations in the Near Tropics by GPS, Microwave Radiometer, and Radiosondes. Journal of Applied Meteorology 40(1):5-15

Nakamura H, Koizumi K, Mannoji N, Seko H (2004) Data Assimilation of GPS Precipitable Water Vapor to the JMA Mesoscale Numerical Weather Prediction Model and its Impact on Rainfall Forecasts. Journal of The Meteorological Society of Japan - J METEOROL SOC JPN 82

Niell AE, Coster AJ, Solheim FS, Mendes VB, Toor PC, Langley RB, Upham CA (2001) Comparison of Measurements of Atmospheric Wet Delay by Radiosonde, Water Vapor Radiometer, GPS, and VLBI. Journal of Atmospheric and Oceanic Technology 18(6):830-850

Ning T, Elgered G, Willn U, Johansson JM (2013) Evaluation of the atmospheric water vapor content in a regional climate model using ground-based GPS measurements. Journal of Geophysical Research: Atmospheres 118(2):329-339, DOI 10.1029/2012JD018053 
Rocken C, Hove TV, Johnson J, Solheim F, Ware R, Bevis M, Chiswell S, Businger S (1995) GPS/STORMGPS Sensing of Atmospheric Water Vapor for Meteorology. Journal of Atmospheric and Oceanic Technology 12(3):468-478

Saastamoinen J (1972) Atmospheric correction for the troposphere and stratosphere in radio ranging satellites. The use of artificial satellites for geodesy 15:247-251

Sapucci LF, Machado LAT, Menezes de Souza E, Campos TB (2016) GPS-PWV jumps before intense rain events. Atmospheric Measurement Techniques Discussions 2016:1-27

Seco A, González P, Ramírez F, García R, Prieto E, Yagüe C, Fernández J (2009) Gps monitoring of the tropical storm delta along the canary islands track, november 28-29, 2005. Pure and applied geophysics 166(8-9):1519-1531

Smith R (2000) The Role of Cumulus Convection in Hurricanes and its Representation in Hurricane Models. Reviews of Geophysics 38

Stacy R, Robbie B (2019) Tropical Cyclone Report: Hurricane Florence (AL062018). Tech. rep., South Carolina, USA

Tahami H, Park J, Choi Y (2017) The preliminary study on the prediction of a hurricane path by gnss derived pwv analysis. In: Proceedings of the ION 2017 Pacific PNT Meeting, Honolulu, Hawaii

Teunissen P, Khodabandeh A (2014) Review and principles of ppp-rtk methods. Journal of Geodesy pp 1-24, DOI 10.1007/s00190-014-0771-3

Vergados P, Mannucci AJ, Su H (2013) A validation study for GPS radio occultation data with moist thermodynamic structure of tropical cyclones. Journal of Geophysical Research: Atmospheres 118(16):9401-9413

Wang J, Zhang L (2008) Systematic Errors in Global Radiosonde Precipitable Water Data from Comparisons with Ground-Based GPS Measurements. Journal of Climate 21(10):2218-2238, DOI 10.1175/2007JCLI1944.1

Wilgan K, Rohm W, Bosy J (2015) Multi-observation meteorological and GNSS data comparison with Numerical Weather Prediction model. Atmospheric Research 156:29 $-42$

Zhang K, Manning T, Wu S, Rohm W, Silcock D, Choy S (2015) Capturing the signature of severe weather events in australia using gps measurements. IEEE Journal of Selected Topics in Applied Earth Observations and Remote Sensing 8(4):1839-1847

Zumberge J, V B Heflin M, Jefferson D, Watkins M, Webb F (1997) Precise Point Positioning for the Efficient And Robust Analysis of GPS Data from Large Networks. Journal of Geophysical Research 102

Zus F, Dick G, Heise S, Wickert J (2015) A forward operator and its adjoint for gps slant total delays. Radio Science 50(5):393-405 